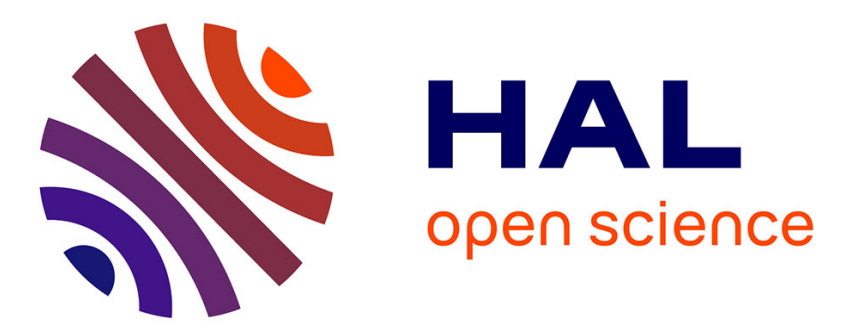

\title{
Athletes' perceptions of role ambiguity and coaching competency in sport teams: A multilevel analysis
}

Gregoire Bosselut, Jean-Philippe Heuzé, Mark A. Eys, Paul Fontayne, Philippe Sarrazin

\section{- To cite this version:}

Gregoire Bosselut, Jean-Philippe Heuzé, Mark A. Eys, Paul Fontayne, Philippe Sarrazin. Athletes' perceptions of role ambiguity and coaching competency in sport teams: A multilevel analysis. Journal of Sport and Exercise Psychology, 2012, 34, pp.354-364. 10.1123/jsep.34.3.345 . hal-00904663

\section{HAL Id: hal-00904663 https://hal.science/hal-00904663}

Submitted on 14 Nov 2013

HAL is a multi-disciplinary open access archive for the deposit and dissemination of scientific research documents, whether they are published or not. The documents may come from teaching and research institutions in France or abroad, or from public or private research centers.
L'archive ouverte pluridisciplinaire HAL, est destinée au dépôt et à la diffusion de documents scientifiques de niveau recherche, publiés ou non, émanant des établissements d'enseignement et de recherche français ou étrangers, des laboratoires publics ou privés. 


\title{
Athletes' Perceptions of Role Ambiguity and Coaching Competency in Sport Teams: A Multilevel Analysis
}

\author{
Grégoire Bosselut, ${ }^{1}$ Jean-Philippe Heuzé, ${ }^{1}$ Mark A. Eys, ${ }^{2}$ \\ Paul Fontayne, ${ }^{3}$ and Philippe Sarrazin ${ }^{1}$ \\ 1Université Joseph Fourier; ${ }^{2}$ Wilfrid Laurier University; \\ 3Université Paris-Ouest Nanterre La Défense
}

\begin{abstract}
The purpose of this study was to examine the relationship between athletes' perceptions of role ambiguity and two theoretically derived dimensions of coaching competency (i.e., game strategy and technique competencies). A total of 243 players from 26 teams representing various interdependent sports completed French versions of the Role Ambiguity Scale and the Coaching Competency Scale. Multilevel analyses supported the existence of relationships between the four dimensions of role ambiguity and the two dimensions of coaching competency at both individual and team levels. When the levels were considered jointly, athletes perceiving greater ambiguity in their role in both offensive and defensive contexts were more critical of their coach's capacities to lead their team during competitions and to diagnose or formulate instructions during training sessions. The results also indicated that the dimension of scope of responsibilities was the main contributor to the relationship with coaching competency at an individual level, whereas role evaluation was the main contributor to this relationship at a group level. Findings are discussed in relation to the role episode model, the role ambiguity dimensions involved in the relationships according to the level of analysis considered, and the salience of ambiguity perceptions in the offensive context.
\end{abstract}

Keywords: role perception, coaching competency, group dynamics, multilevel analysis

Role ambiguity - the lack of clear, consistent information regarding an individual's role (Kahn, Wolfe, Quinn, Snoek, \& Rosenthal, 1964) —is the most widely investigated element of role involvement in a sport context (Eys, Beauchamp, \& Bray, 2006). Recent works by Beauchamp and colleagues (e.g., Beauchamp \& Bray, 2001; Beauchamp, Bray, Eys, \& Carron, 2002; Eys \& Carron, 2001) to develop a

Grégoire Bosselut and Jean-Philippe Heuzé are with Université Joseph Fourier, Grenoble, France. Mark A. Eys is with Wilfrid Laurier University, Waterloo, Canada. Paul Fontayne is with Université Paris-Ouest Nanterre La Défense, France. Philippe Sarrazin is with Université Joseph Fourier, Grenoble, France. 
conceptual model has spurred further research toward understanding this concept (see Eys et al., 2006, for a review). In this conceptual model, Beauchamp et al. (2002) underlined four manifestations of role ambiguity: scope of responsibilities (i.e., an athlete's knowledge of the extent of his/her responsibilities), role behaviors (i.e., an athlete's knowledge of the specific behaviors necessary to fulfill that role), role evaluation (i.e., an athlete's knowledge of how he/she is evaluated in performing his/her role behaviors), and role consequences (i.e., an athlete's knowledge of the punishments/frustrations associated with not fulfilling his/her role responsibilities). In addition, the researchers proposed that these four manifestations can occur in the separate contexts of offense and defense.

In discussing the process by which role information is communicated in sport, Eys, Carron, Beauchamp, and Bray (2005) adapted the role episode model proposed by Kahn and his colleagues (1964) that was originally developed for organizational settings. Kahn et al.'s model highlights the interaction between two central actors in a group; the role sender (i.e., the individual who assigns role expectations; e.g., coach) and the focal person (i.e., the individual who must fulfill role expectations; e.g., athlete). The model also specifies five events that occur during the communication, reception, and execution of a role and its associated responsibilities. During the first event, the role sender develops expectations about the role to be carried out by the focal person. This is followed by the role sender communicating these expectations to, and exerting pressure on, the focal person. The focal person perceives these expectations in a variety of ways (e.g., with clarity; in conflict with other expectations) during the third event. Subsequently, during the fourth event, the focal person produces cognitive, affective, and behavioral responses to the expectations communicated to him or her. During the fifth event, the role sender interprets the responses of the focal person, which influences current and future role expectations. These five events represent the core of the role episode model, underline the cyclical nature of the model, and describe a causal sequence (Kahn et al., 1964).

In the sport context, common occupants of the role sender and the focal person are the coach and athlete, respectively (Eys et al., 2005). Typically in sport teams, the coach is the primary source of role-related expectations (Beauchamp, Bray, Eys, \& Carron, 2005) in that he or she specifies in detail what is expected of athletes, provides instruction, and gives feedback. Consequently, researchers previously investigated the coach as a source of athletes' perceptions of role ambiguity (Beauchamp, Bray, Eys, \& Carron, 2005; Eys et al., 2005; Mellalieu \& Juniper, 2006). In two qualitative studies, team players described their coach as the major source of role ambiguity in their sport (Eys et al., 2005; Mellalieu \& Juniper, 2006). In a quantitative study, Beauchamp, Bray, Eys, and Carron (2005) examined the relationship between athletes' perceptions of coaching behaviors and role ambiguity. The authors noted that, for nonstarters, higher perceptions of the frequency of coaches' training and instruction behaviors were associated with lower perceptions of ambiguity regarding offensive and defensive role consequences as well as lower perceptions of ambiguity regarding offensive role evaluation. For starters, no significant relationships were found. Beauchamp and his colleagues discussed their results in light of the operational definition of leadership used in their study (i.e., the Leadership Scale for Sports; Chelladurai \& Saleh, 1980), which focused on the frequency of leadership behaviors rather than on their quality. Beauchamp, Bray, 
Eys, and Carron (2005) raised the possibility that "it is not the amount or intensity of training and instructional leadership that is important but rather the proficiency of leadership required to meet the needs of each role incumbent" (p. 16).

Interestingly, recent research has described a useful framework from which to examine the issue of athletes' perceptions of their coach's capacity to influence their behaviors (i.e., proficiency of leadership/coaching behaviors). Initially, Feltz, Chase, Moritz, and Sullivan (1999) developed a conceptual model of coaching efficacy to provide a framework for studying the relationships among coaching efficacy, coaching behavior, and the motivation and performance of athletes (see Feltz, Short, \& Sullivan, 2008, for a review). Based on this conceptual model, Myers, Feltz, Maier, Wolfe, and Reckase (2006) advanced the construct of coaching competency, which refers to athletes' evaluations of their head coach's ability to (a) affect their psychological mood and skills (i.e., motivation competence, MC), (b) positively influence their character development through sport ${ }^{1}$ (i.e., character building competence, CBC), (c) lead during competition (i.e., game strategy competence, GSC), and (d) instruct and make diagnoses during practices ${ }^{2}$ (technique competence, TC). Recently, Myers, Chase, Beauchamp, and Jackson (2010) defined a fifth dimension (i.e., physical conditioning competence, PCC) that refers to athletes' perceptions of their head coach's ability to prepare his or her athletes physically for sport participation.

Coaching competency has important implications in the sport context. The recent development of the Coaching Competency Scale (CCS; Myers, Feltz, et al., 2006) and the Athletes' Perceptions of Coaching Competency Scale II-High school Teams (APCCS II-HST; Myers et al., 2010) allows researchers to explore perceptions of coaching competency, although only two studies to date have examined this construct in relation to athletes' satisfaction with their head coach (Myers, Beauchamp, \& Chase, 2011; Myers, Wolfe, Maier, Feltz, \& Reckase, 2006). At the individual athlete level of analysis, the results supported a moderately large, positive relationship between MC and satisfaction with the coach within a sample of intercollegiate teams (Myers, Wolfe, et al., 2006) and a larger positive relationship between MC and TC and satisfaction with the coach within a sample of high school teams (Myers et al., 2011). The results also indicated that coaching competency exerted a large positive effect on satisfaction with the coach at the team/group level of analysis (Myers et al., 2011).

As a brief summary of the above review, (a) previous studies using both qualitative and quantitative approaches identified the coach as a primary source of role information for athletes, (b) the frequency of certain coaching behaviors was linked to perceptions of role ambiguity, and (c) recent theorizing and measurement development pertaining to athletes' perceptions of coaching competencies allows for important insights into the quality of the role sender's behaviors, affording the opportunity to examine Beauchamp, Bray, Eys, and Carron's (2005) future research direction pertaining to the link between the proficiency of leadership behaviors and role ambiguity. However, in their role episode model, Kahn and his colleagues (1964) advanced that perceptions of role ambiguity influenced interpersonal relations (i.e., power or ability to influence) between the focal person and the role sender. Given that coaching competency refers to athletes' perceptions of their coach's ability to influence them (i.e., mood, character, motivation, competence, performance), the purpose of the current study was to examine the relationship 
between role ambiguity and one cognitive aspect of the focal person's response: the athlete's evaluation of his or her coach's competencies.

Following Myers, Feltz, et al. (2006), who recommended that an a priori determination should be made as to which competency measure is used, we did not consider all coaching competency dimensions. Given that game strategy competence refers to the use of effective tactical skills by coaches, which are based on coaches' expectations about the roles to be carried out by teammates, a negative relationship was hypothesized between athletes' perceptions of role ambiguity and GSC. Moreover, technique competence refers to the detection of skill errors, the use of individualized instruction, and corrective feedback (i.e., addressing specific behaviors necessary for role fulfillment by the athlete). Given that athletes previously explained that role clarity developed through explicit instruction and feedback from coaches (Mellalieu \& Juniper, 2006), a negative relationship was also hypothesized between athletes' perceptions of role ambiguity and TC. The three remaining dimensions of coaching competency (i.e., motivation, character building, and physical conditioning competencies) do not directly refer to the roles fulfilled by teammates. As a result, they were not considered in the current study.

Finally, given the nature and context of the study, it was important to consider the multilevel structure of the data. Indeed, participants were members of sport teams and, as a result, athletes within the same team may hold perceptions of the study variables that are more similar compared with athletes across different teams. Thus, from a statistical point of view, multilevel modeling was needed to decompose the relationship between role ambiguity and coaching competency into separate within-group and between-group components, decreasing the likelihood of Type I error (for a full discussion, see Papaioannou, Marsh, \& Theodorakis, 2004; Raudenbush \& Bryk, 2002).

However, a multilevel approach does not only answer the problem of the nonindependence of the data, but it also allows researchers to consider questions that have theoretical relevance (Papaioannou et al., 2004). First, examining the relationship between two constructs at only one level (i.e., either the individual level or the group level) may lead researchers to assume that the relationship is identical at each level. This is not an assumption that can be made. For example, Myers et al. (2011) noted that the dimensions of coaching competency involved in the relationships with athletes' satisfaction with the head coach differed according to the considered level (i.e., technique competence and motivation competence were relevant at the individual level while a more general dimension of coaching competency was relevant at the team level). Second, in a similar vein, single-level research may miss important information that is present at the level not considered (e.g., Kashy \& Kenny, 2000). As a result, it limits the understanding of how the relationship between two constructs might differentially vary from team to team, and the characteristics of teams associated with this variation (Beauchamp, Bray, Fielding, \& Eys, 2005; Papaioannou et al., 2004). Third, a multilevel approach allows researchers to pose hypotheses about relations occurring at each level and across levels and also to assess the amount of variation at each level (Raudenbush \& Bryk, 2002). In the current study, such an approach may determine the extent to which role ambiguity, defined at either the individual or group level, explains variance in coaching competency at the same level and at the other. It may also determine at which level the strength of the relationship is higher between the two variables. 
Both constructs examined in the current study (i.e., role ambiguity and coaching competency) have been discussed and examined using a multilevel approach (Beauchamp, Bray, Fielding, \& Eys, 2005; Myers et al., 2010, 2011; Myers, Feltz, et al., 2006; Myers, Wolfe, et al., 2006). The authors of these previous studies found that the majority of the variance was nested at the individual level. Thus, in the current study, it was hypothesized that the strength of the negative relationship between role ambiguity and coaching competency would be higher at the individual level than at the team level.

\section{Method}

\section{Participants}

The sample consisted of 243 players (186 starters and 57 nonstarters) from 26 teams $(M=23.09$ years old, $S D=4.10 ;$ range $=16-39$ years old; 200 men and 43 women) of various interdependent sports (i.e., basketball, handball, ice hockey, roller hockey, rugby, soccer, volleyball, water polo). This represented an average of 9.72 players per team $(S D=4.51$; range $=4-19)$. These athletes were members of their respective teams for $2.79 \pm 2.36$ years and possessed $10.95 \pm 5.35$ years of experience in their sport. Three levels of play were represented within the sample: (a) subdistrict area $(n=44, g=7)$, (b) district area $(n=72, g=6)$, and (c) national level ( $n=127, g=13$ ); these descriptions reflect competitive and formal sport contexts from which reasonable perceptions of coaching competency and role ambiguity can be derived.

\section{Measures}

Role Ambiguity. Role ambiguity was measured using the Echelle d'Ambiguïté $d u$ Rôle-34 (EAR-34; Bosselut, Heuzé, \& Sarrazin, 2010), a French version of the Role Ambiguity Scale (Beauchamp et al., 2002). This is a 34-item instrument designed to assess the four dimensions of role ambiguity in both offensive and defensive contexts: scope of responsibilities (four items in each context; e.g., "I understand the extent of my defensive [offensive] responsibilities"); role behaviors (four items in each context; e.g., "I understand what adjustments to my behavior need to be made to carry out my role in defense [in offense]"); role evaluation (five items in each context; e.g., "I understand the criteria by which my defensive [offensive] role responsibilities are evaluated"); and role consequences (five items in each context; e.g., "It is clear to me what happens if I fail to carry out my defensive [offensive] role responsibilities"). Athletes rated their agreement with each item on a 9-point Likert-type scale anchored by 1 (strongly disagree) and 9 (strongly agree), with higher scores reflecting greater role clarity (i.e., less role ambiguity). Participants' responses to items were averaged to yield scale/dimension scores.

Support for the construct and predictive validity, as well as the reliability of the French questionnaire was provided by Bosselut et al. (2010). However, in the French culture, Bosselut et al.'s results did not clearly indicate whether role ambiguity was best conceived as a three- or four-dimension construct (i.e., high correlations were found between scope of responsibilities and role behaviors). Therefore, for both offensive and defensive contexts, confirmatory factor analyses were carried out using the AMOS (version 4.0) program (Arbuckle, 1999) with the 
Table 1 Descriptive Statistics for Role Ambiguity and Coaching Competency

\begin{tabular}{lccc}
\hline & $\boldsymbol{M}$ & SD & $\theta$ \\
\hline Offensive & & & \\
Scope & 7.03 & 1.14 & .79 \\
Behaviors & 7.07 & 1.04 & .78 \\
Evaluation & 6.74 & 1.19 & .79 \\
Consequences & 6.95 & 1.21 & .75 \\
Defensive & & & \\
Scope & 7.32 & 1.06 & .83 \\
Behaviors & 7.27 & 0.98 & .80 \\
Evaluation & 6.98 & 1.18 & .85 \\
Consequences & 7.23 & 1.17 & .82 \\
Coaching competency & & & .86 \\
GSC & 4.16 & 0.58 & .80 \\
TC & 4.17 & 0.65 & \\
\hline
\end{tabular}

Note. GSC $=$ Game strategy competence; TC $=$ Technique competence; $\theta=[p /(p-1)] \times\left[1-\left(1 / \lambda_{1}\right)\right]$ where $p$ is the number of items in the scale and $\lambda_{1}$ is the largest eigenvalue from the principal component analysis of the items involved in the composite (see, Zumbo et al., 2007, p. 22).

bootstrap maximum likelihood estimates (i.e., observed variables were correlated and their distributions moved away from normality). In the offensive context, the results provided evidence for a four-factor structure, Comparative Fit Index $(\mathrm{CFI}$; Bentler, 1990) = .98, Normative Fit Index (NFI; Bentler \& Bonett, 1980) $=.98$, Root Mean Square Error of Approximation (RMSEA; Browne \& Cudeck, $1989)=.07$, Expected Cross Validation Index (ECVI; Browne \& Cudeck, 1993) $=1.70$, and Akaike's Information Criterion (AIC; Akaike, 1973) $=371.57$. In the defensive context, the results also provided evidence for a four-factor structure, $\mathrm{CFI}=.98, \mathrm{NFI}=.98, \mathrm{RMSEA}=.07, \mathrm{ECVI}=1.70$, and $\mathrm{AIC}=373.93$. Using theta coefficients for ordinal distribution (see Zumbo, Gadermann, \& Zeisser, 2007), the internal consistencies of the role ambiguity manifestations (see Table 1) were found to be acceptable.

Coaching Competency. Coaching competency was assessed using the Echelle de Compétence du Coaching (ECC; Bosselut, 2008), a French version of the Coaching Competency Scale (CCS; Myers, Feltz, et al., 2006; Myers, Wolfe, et al., 2006). With respect to the hypotheses advanced in the current study, only two dimensions were considered: game strategy competence (seven items; e.g., "How competent is your head coach in his or her ability to understand competitive strategies") and technique competence (six items; e.g., "How competent is your head coach in his or her ability to detect skill errors during practice"). In comparison with the original version of the CCS, and following Myers, Wolfe, et al.'s (2006) recommendations, (a) a revised operational definition of technique competence (i.e., focusing on 
instructional and diagnostic abilities during practices only) and (b) a 5-point Likerttype scale were used, with response options ranging from 1 (complete incompetence) to 5 (complete competence). Thus, higher scores represented higher perceptions of coaching competency. Again, participants' responses were averaged to yield scale/dimension scores. Support for the construct and predictive validity, as well as the reliability of the ECC were provided by Bosselut (2008). In the current study, a CFA was conducted and results provided evidence for a two-factor structure, $\mathrm{CFI}=.98, \mathrm{NFI}=.98, \mathrm{RMSEA}=.09, \mathrm{ECVI}=1.19$, and $\mathrm{AIC}=268.18$. For each dimension, acceptable internal consistency (theta coefficients; Zumbo et al., 2007) was recorded (see Table 1).

\section{Procedure}

Initial contact with team coaches was made by phone by the first two authors. The purpose and the procedure of the study were explained to coaches and their permission to include their teams in the study was obtained. Once permission was granted to approach the athletes, an informed consent was obtained from each participant. The questionnaires (EAR-34 and ECC) were administered by one of the authors before team training sessions in the middle of a training week (i.e., games were generally played on Saturday evenings) in the middle of the season. This timing of test administration ensured sufficient experience from which players could make informed judgments. Once confidentiality was assured to the athletes, they read the instructions written on the questionnaires and completed them independently without conversing with their teammates. Questionnaires were returned directly to the researchers upon completion.

\section{Data analysis}

The multilevel structure of the data (i.e., athletes nested within teams) required the application of multilevel modeling. Hierarchical linear modeling (HLM; Rasbash et al., 2000) simultaneously tests the effects at both levels (i.e., individual and group) and their interaction on the dependent variable. The level of analysis of the group was random, allowing a more precise estimate of the residuals to be obtained, unlike traditional regression analyses. Both role ambiguity and coaching competency data were standardized ( $z$ scored) (see Rasbash et al., 2000; Raudenbush \& Bryk, 2002) in consideration of (a) the two different ordered response levels (i.e., 9 vs. 5 , respectively) used to assess the variables and (b) producing meaningful intercept parameters. The multilevel analysis was performed using the MLwiN-2 program to test several sets of models of increasing complexity.

In these models, each dependent variable (each dimension of coaching competency) is represented by the term $Y_{i j}$, where $i$ represents an observation of individual within a team $j$ (Equation 1 ). Similarly, each explanatory variable (e.g., each dimension of role ambiguity) is represented by the term $X$ by distinguishing the individual $(i)$ and group $(j)$ levels. A fixed coefficient of regression, $\beta_{1}$, is added:

$$
Y_{i j}=\beta_{0 i j} X_{0}+\beta_{1} X_{1 i j}
$$

The term $\beta_{0 i j}$ presented in this equation (Equation 1) represents the sum of three terms, $\beta_{0 i j}=\beta_{0}+u_{0 j}+e_{i j}$, where $\beta_{0}$ is an average fixed intercept of the overall 
sample, $u_{0 j}$ is the deviation of the intercept compared with the team $j$, and $e_{i j}$ is the deviation of the constant of players $i$ in each team $j$. Thus, the model associates one dimension of coaching competency to one manifestation of role ambiguity recognizing the random part of the constant variation on the group level.

In a traditional regression, the constant and the slope are fixed. Here, in Equation 1 , the constant is allowed to vary across teams. The multilevel analysis may further specify the slope coefficient for the role ambiguity to vary on a second level (i.e., the team). The variation of slope is indicated in the new equation (Equation 2) by adding the indicator of the team (i.e., $j$ ) to the coefficient $\beta_{1}$, which becomes $\beta_{1 j}$.

$$
Y_{i j}=\beta_{0 i j} X_{0}+\beta_{1 j} X_{1 i j}
$$

Various types of models were tested; the first model (Model A; Equation 3; see Tables 2 and 4) is a null model without any predictor at any level.

$$
Y_{i j}=\beta_{0 j}+e_{i j}
$$

where $\beta_{0 j}=\beta_{0}+u_{0 j}$. This model informs about the degree of similarity between team members as compared with the players of other teams.

Then, intrateam correlations (ICC; Equation 4) are calculated for the dependent variables (i.e., coaching competency dimensions).

$$
\sigma^{2}{ }_{u 0} /\left(\sigma^{2}{ }_{u 0}+\sigma_{e}^{2}\right)
$$

In this equation, $\sigma^{2}{ }_{u 0}$ indicates the variance between the groups and $\sigma^{2}{ }_{e}$ the variance between the individuals within a group. This coefficient can also be interpreted as the proportion of the total residual variation due to the differences between the groups. Higher intrateam correlations reflect greater similarity between the responses of players within the same team.

Then, control variables can be added in the relationship between the dependent and the explanatory variables, successively. As several studies underlined an influence of status and gender on perceptions of role ambiguity (e.g., Beauchamp, Bray, Eys, \& Carron, 2005; Cunningham \& Eys, 2007; Eys \& Carron, 2001) and coaching competency (Bosselut, 2008), status, gender, and their interaction were introduced as control variables (Model B; Equation 5; see Tables 2 and 4).

$$
Y_{i j}=\beta_{0 j}+\beta_{1} X_{1 i j}+\beta_{2} X_{2 i j}+\beta_{3} X_{3 i j}+e_{i j}
$$

where $X_{1}=$ gender, $X_{2}=$ status, and $X_{3}=$ gender $\times$ status.

In the third model (Model C; Equation 6; see Tables 2, 4), one role ambiguity manifestation was added as a predictor of one coaching competency dimension.

$$
\mathrm{Y}_{i j}=\beta_{0 j}+\beta_{1} X_{1 i j}+\beta_{2} X_{2 i j}+\beta_{3} X_{3 i j}+\beta_{4} X_{4 i j}+e_{i j}
$$

where $X_{1}=$ gender, $X_{2}=$ status, $X_{3}=$ gender $\times$ status, and $X_{4}=$ scope, behaviors, evaluation, and consequences, successively. To determine the best model compared with the preceding model including fewer parameters, an examination of the deviance, $-2 \log$ likelihood $\left(\chi^{2}\right)$ statistic (depending on degree of freedom) is required. A significant reduction in this indicator after the introduction of a new variable (or a new set of variables) indicates an improvement of the adequacy of the data compared with the previous model. 
Table 2 Variance Component Models A, B, and C for Technique Competence

\begin{tabular}{|c|c|c|c|c|c|c|c|c|c|c|}
\hline \multirow[b]{2}{*}{ Parameter } & \multirow{2}{*}{$\begin{array}{c}\text { Model A } \\
\text { Estimates (SE) }\end{array}$} & \multirow{2}{*}{$\begin{array}{c}\text { Model B } \\
\text { Estimates (SE) }\end{array}$} & \multicolumn{4}{|c|}{ Model C Estimates (SE): Offense } & \multicolumn{4}{|c|}{ Model C Estimates (SE): Defense } \\
\hline & & & Scope & Behaviors & Evaluation & Conseq. & Scope & Behaviors & Evaluation & Conseq. \\
\hline \multicolumn{11}{|l|}{ Fixed } \\
\hline \multirow[t]{2}{*}{ Intercept } & -0.042 & -0.036 & -0.045 & -0.040 & -0.034 & -0.046 & -0.032 & -0.032 & -0.031 & -0.034 \\
\hline & $(0.109)$ & $(0.106)$ & $(0.103)$ & $(0.107)$ & $(0.100)$ & $(0.108)$ & $(0.106)$ & $(0.106)$ & $(0.101)$ & $(0.108)$ \\
\hline \multirow[t]{2}{*}{ Gender } & - & 0.028 & 0.002 & 0.027 & 0.041 & 0.019 & 0.002 & 0.014 & 0.039 & 0.026 \\
\hline & & $(0.097)$ & $(0.095)$ & $(0.098)$ & $(0.092)$ & $(0.099)$ & $(0.097)$ & $(0.098)$ & $(0.093)$ & $(0.099)$ \\
\hline \multirow[t]{2}{*}{ Status } & - & -0.163 & -0.152 & -0.149 & -0.151 & -0.110 & -0.173 & -0.170 & -0.196 & -0.154 \\
\hline & & $(0.061)^{* *}$ & $(0.057)^{* *}$ & $(0.059)^{*}$ & $(0.059)^{*}$ & $(0.061)$ & $(0.060)^{* *}$ & $(0.060)^{* *}$ & $(0.060) * * *$ & $(0.061)^{*}$ \\
\hline \multirow[t]{2}{*}{ Gender $\times$ Status } & - & -0.059 & -0.074 & -0.073 & -0.037 & -0.065 & -0.061 & -0.074 & -0.059 & -0.057 \\
\hline & & $(0.067)$ & $(0.063)$ & $(0.065)$ & $(0.064)$ & $(0.065)$ & $(0.066)$ & $(0.065)$ & $(0.065)$ & $(0.066)$ \\
\hline \multirow[t]{2}{*}{ Role Ambiguity } & - & - & 0.332 & 0.238 & 0.273 & 0.225 & 0.169 & 0.219 & 0.249 & 0.102 \\
\hline & & & $(0.061)^{* * *}$ & $(0.061)^{* *}$ & $(0.061)^{* * *}$ & $(0.063)^{* * *}$ & $(0.063)^{* *}$ & $(0.062)^{* * *}$ & $(0.062)^{* * *}$ & $(0.063)$ \\
\hline \multicolumn{11}{|l|}{ Random } \\
\hline \multirow[t]{2}{*}{ Team $\sigma_{\mathrm{u} 0}^{2}$} & $0.248 \backslash$ & 0.225 & 0.226 & 0.239 & 0.196 & 0.251 & 0.227 & 0.235 & 0.197 & 0.238 \\
\hline & $(0.098)^{*}$ & $(0.091)^{*}$ & $(0.087)^{*}$ & $(0.093)^{*}$ & $(0.081)^{*}$ & $(0.096) * *$ & $(0.091)^{*}$ & $(0.092)^{*}$ & $(0.082)^{*}$ & $(0.094)^{*}$ \\
\hline \multirow[t]{2}{*}{ Individual $\sigma_{\mathrm{e}}^{2}$} & 0.774 & 0.754 & 0.657 & 0.695 & 0.698 & 0.702 & 0.727 & 0.708 & 0.708 & 0.740 \\
\hline & $(0.080)^{* * *}$ & $(0.078) * * *$ & $(0.085)^{* * *}$ & $(0.072)^{* * *}$ & $(0.072)^{* * *}$ & $(0.072)^{* * *}$ & $(0.075)^{* * *}$ & $(0.073)^{* * *}$ & $(0.073)^{* * *}$ & $(0.076) * * *$ \\
\hline ICC & 0.24 & 0.23 & 0.26 & 0.26 & 0.22 & 0.26 & 0.24 & 0.25 & 0.22 & 0.24 \\
\hline$-2 * \operatorname{LL}\left(\chi^{2}\right)$ & 608.039 & 600.760 & 572.937 & 586.299 & 581.576 & 588.605 & 593.589 & 588.889 & 585.163 & 598.219 \\
\hline$\Delta \chi^{2 \mathrm{a}, \mathrm{b}}$ & & $7.279^{\mathrm{a}}$ & $27.823^{\mathrm{b} * * *}$ & $14.461^{\mathrm{b} * * *}$ & $19.184^{\mathrm{b} * * *}$ & $12.155^{\mathrm{b} * * *}$ & $7.171^{b * *}$ & $11.871^{\mathrm{b} * * *}$ & $15.597^{\mathrm{b} * * *}$ & $2.541^{\mathrm{b}}$ \\
\hline
\end{tabular}


Finally, a last model (Model D; see Tables 3 and 5) was tested. In this model, all role ambiguity manifestations (i.e., Scope, Behaviors, Evaluation, and Consequences) were entered in the equation (see Equation 7) as predictors of one coaching competency dimension.

$$
Y_{i j}=\beta_{0 j}+\beta_{1} X_{1 i j}+\beta_{2} X_{2 i j}+\beta_{3} X_{3 i j}+\beta_{4} X_{4 i j}+\beta_{5} X_{5 i j}+\beta_{6} X_{6 i j}+\beta_{7} X_{7 i j}+e_{i j}
$$

where $X_{1}=$ gender, $X_{2}=$ status, $X_{3}=$ gender $\times$ status, $X_{4}=$ scope, $X_{5}=$ behaviors, $X_{6}=$ evaluation, and $X_{7}=$ consequences.

The following sections describe these two series of models successively which intended to predict two dimensions of the athletes' evaluations of their head coach's coaching competency: (a) technique competence and (b) game strategy competence.

\section{Table 3 Variance Component Model D for Technique Competence}

\begin{tabular}{|c|c|c|}
\hline \multirow[b]{2}{*}{ Parameter } & \multicolumn{2}{|c|}{ Model D Estimates (SE) } \\
\hline & Offense & Defense \\
\hline \multicolumn{3}{|l|}{ Fixed } \\
\hline Intercept & $-0.045(0.102)$ & $-0.031(0.101)$ \\
\hline Gender & $0.007(0.095)$ & $0.031(0.093)$ \\
\hline Status & $-0.140(0.059)^{*}$ & $-0.198(0.061)^{* * *}$ \\
\hline Gender $\times$ Status & $-0.061(0.063)$ & $-0.068(0.065)$ \\
\hline \multicolumn{3}{|l|}{ Role Ambiguity } \\
\hline Scope & $0.304(0.101)^{* *}$ & $-0.025(0.104)$ \\
\hline Behaviors & $-0.088(0.099)$ & $0.134(0.104)$ \\
\hline Evaluation & $0.099(0.087)$ & $0.207(0.083)^{*}$ \\
\hline Consequences & $0.058(0.076)$ & $-0.054(0.077)$ \\
\hline \multicolumn{3}{|l|}{ Random } \\
\hline Team $\sigma_{\mathrm{u} 0}^{2}$ & $0.219(0.085) * *$ & $0.200(0.082)^{*}$ \\
\hline Individual $\sigma_{\mathrm{e}}^{2}$ & $0.650(0.067)^{* * * *}$ & $0.699(0.072)^{* * *}$ \\
\hline ICC & 0.25 & 0.22 \\
\hline$-2 * \operatorname{LL}\left(\chi^{2}\right)$ & 570.121 & 582.873 \\
\hline$\Delta \chi^{2 \mathrm{a}, \mathrm{b}}$ & $30.639 \mathrm{~b} * * *$ & $17.887^{\mathrm{b} * *}$ \\
\hline
\end{tabular}

Note. Team $\sigma^{2} \mathrm{u} 0=$ Team-level variance; Individual $\sigma^{2} \mathrm{e}=$ Individual-level variance; $\mathrm{ICC}=$ Intrateam correlation; $-2 * \operatorname{LL}\left(\chi^{2}\right)=\log$ likelihood; $\Delta \chi^{2}=\log$ variation ( ${ }^{\mathrm{a}}$ with model A; ${ }^{\mathrm{b}}$ with model B); ${ }^{*} p<.05$; $* * p<.01$; *** $p<.001$. 
Table 4 Variance Component Models A, B, and C for Game Strategy Competence

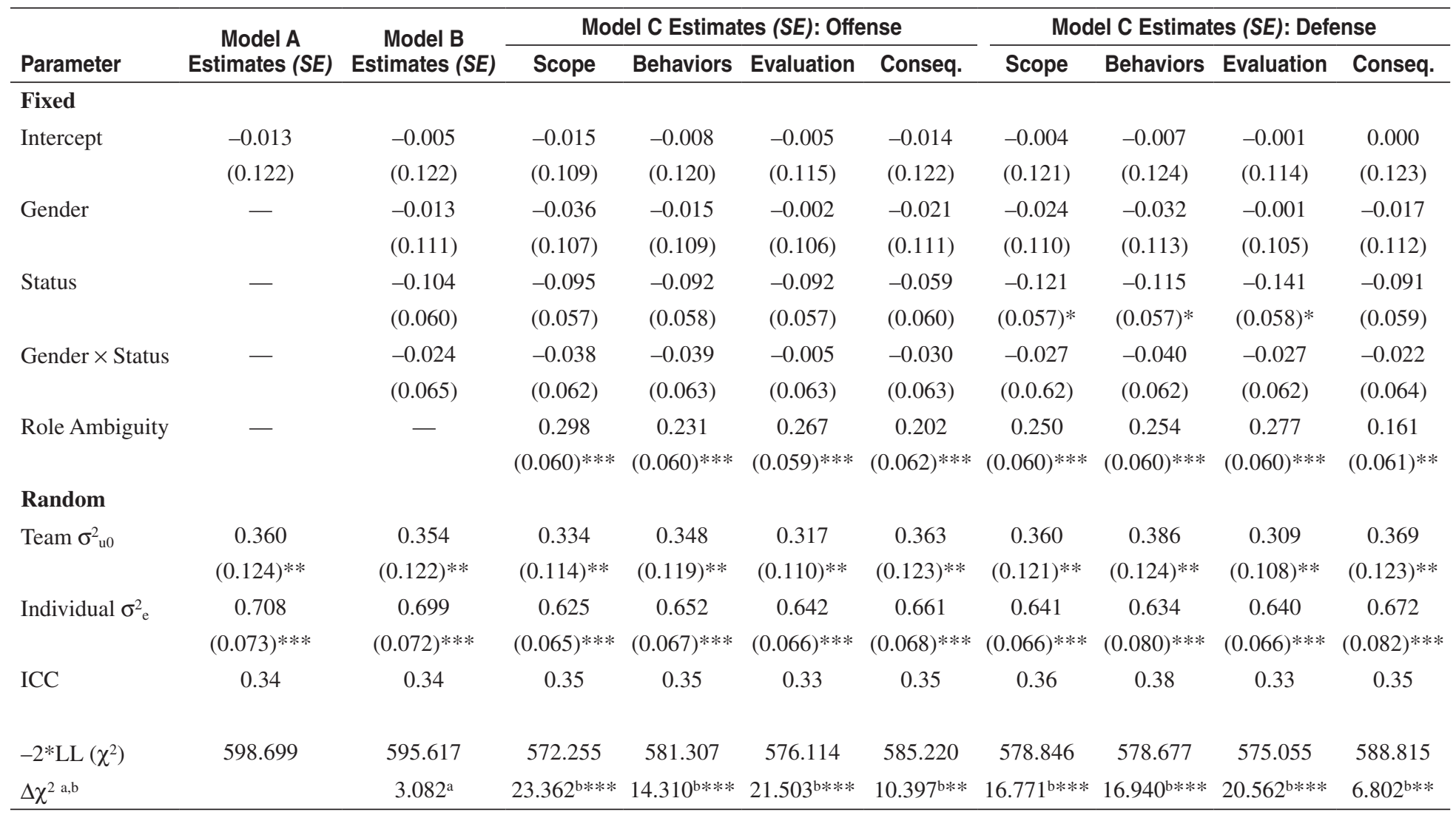


Table 5 Variance Component Model D for Game Strategy Competence

\begin{tabular}{lcc}
\hline & \multicolumn{2}{c}{ Model D Estimates (SE) } \\
\cline { 2 - 3 } Parameter & Offense & Defense \\
\hline Fixed & $-0.013(0.116)$ & $-0.006(0.107)$ \\
Intercept & $-0.025(0.106)$ & $0.013(0.107)$ \\
Gender & $-0.086(0.058)^{*}$ & $-0.198(0.061)^{* * *}$ \\
Status & $-0.023(0.023)$ & $-0.068(0.065)$ \\
Gender $\times$ Status & & \\
Role Ambiguity & $0.229(0.099)^{*}$ & $0.102(0.100)$ \\
$\quad$ Scope & $-0.046(0.098)$ & $0.066(0.100)$ \\
$\quad$ Behaviors & $0.130(0.086)$ & $0.184(0.080)^{*}$ \\
$\quad$ Evaluation & $0.035(0.075)$ & $-0.021(0.074)$ \\
$\quad$ Consequences & & $0.334(0.114)^{*}$ \\
Random & $0.325(0.111)^{* *}$ & $0.622(0.064)^{* * *}$ \\
Team $\sigma^{2}{ }_{\mathrm{u} 0}$ & $0.617(0.064)^{* * *}$ & 0.35 \\
Individual $\sigma_{\mathrm{e}}^{2}$ & 0.34 & 571.259 \\
ICC & & $24.358^{\mathrm{b} * * *}$ \\
$-2 * \mathrm{LL}\left(\chi^{2}\right)$ & 568.955 & \\
$\Delta \chi^{2} \mathrm{a}, \mathrm{b}$ & $26.662^{\mathrm{b} * * *}$ & \\
\hline
\end{tabular}

Note. Team $\sigma^{2} \mathrm{u} 0=$ Team-level variance; Individual $\sigma^{2} \mathrm{e}=$ Individual-level variance; $\mathrm{ICC}=$ Intrateam correlation; $-2 * \operatorname{LL}\left(\chi^{2}\right)=\log$ likelihood; $\Delta \chi^{2}=\log$ variation ( ${ }^{\mathrm{a}}$ with model $\mathrm{A} ;{ }^{\mathrm{b}}$ with model B); ${ }^{*} p<.05$; $* * p<.01 ; * * * p<.001$.

\section{Results}

\section{Descriptive Statistics}

Univariate (i.e., $|z|>3.29$ for $p<.001$ ) and multivariate (i.e., Mahalanobis distance lower than $\left.\chi^{2}(10)=23.21, p<.001\right)$ outliers were excluded from further analyses. Using Tabachnick and Fidell's (2007) recommendations, a dummy variable was created categorizing participants as nonoutliers or outliers (i.e., 0,1$)$. Then, this dummy variable was used as the dependent variable in a stepwise regression with all role ambiguity and coaching competency dimensions as independent variables. Results indicated that role evaluation in defense, $R^{2}=.15, F(1,226)=41.23, p<$ .001 , role consequences in offense, $R^{2}=.21, F(1,226)=30.80, p<.001$, and TC, $R^{2}$ $=.24, F(1,226)=25.25, p<.001$, were the dimensions that distinguished outliers from the included cases $\left(M_{\text {role evaluation in defense }}=5.02\right.$ and $6.98 ; M_{\text {role consequences in offense }}$ $=5.21$ and 7.00; $M_{\mathrm{TC}}=5.07$ and 6.81 for outliers and included cases, respectively). 
Consequently, descriptive statistics are based on 226 athletes. Means, standard deviations, and theta coefficients for role ambiguity and coaching competency are presented in Table 1.

\section{Role Ambiguity and Technique Competence (TC)}

Results of the multilevel analysis for technique competence are presented in Tables 2 and 3. For Model A, 24\% of the variance in TC was explained at the team level (i.e., ICC) leaving $76 \%$ of the variance at the individual level. Adding "status," "gender," and "status $\times$ gender" interaction (Model B) did not improve the model; a nonsignificant reduction in the $\chi^{2}$ statistic was noted $\left(\Delta \chi^{2}\right.$ ModelsB-A $=7.279, p>$ $.05)$. However, results also indicated that status $(\beta=-0.163, p<.01)$ was related to perceptions of TC. Thus, Model B was retained (status was statistically controlled) and the following models were compared with this one. When each manifestation of role ambiguity was added in the equation (Model $\mathrm{C}$ ) the new model fit better than Model B (see Table 2; significant variations of the $\chi^{2}$ with $p<.001$ and $\beta$ significant with $p<.01$ ) except for the manifestation of ambiguity associated with the consequences related to the defensive role $\Delta \chi^{2}$ ModelsC-B $=2.541, p<.001 ; \beta=$ $0.102, p>.05)$. Overall, the positive sign of the $\beta$ indicated that weaker perceptions of role ambiguity in both contexts were associated with higher perceptions of TC (higher scores on the EAR-34 reflect higher perceptions of role clarity).

At the individual level, in the offensive context, after controlling for "gender," "status," and their interaction, $12.86 \%$ (i.e., [0.754-0.657]/0.754) of the variance in TC was explained by scope of responsibilities, 7.82\% (i.e., [0.754-0.695]/0.754) by role behaviors, $7.43 \%$ (i.e., [0.754-0.698]/0.754) by role evaluation, and $6.90 \%$ (i.e., $[0.754-0.702] / 0.754)$ by role consequences. In the defensive context, after controlling for "gender," "status," and their interaction, $3.58 \%$ (i.e., [0.754-0.727]/0.754) of the variance in TC was explained by scope of responsibilities, $6.10 \%$ (i.e., [0.754-0.708]/0.754) by role behaviors, 6.10\% (i.e., [0.754-0.708]/0.754) by role evaluation, and $1.86 \%$ (i.e., [0.754-0.740]/0.754) by role consequences.

At the team level, after controlling for "status," "gender," and their interaction, no improvement in the amount of explained variance in TC was noted except for role evaluation in the offensive context (i.e., 12.89\%; [0.225-0.196]/0.225) and defensive context (i.e., $12.44 \%$; [0.225-0.197]/0.225). Thus, at the individual level, role ambiguity negatively predicted the athletes' evaluations of their head coaches' TC and scope of responsibilities constituted the major manifestation in this relationship. At the team level, only role evaluation in both contexts explained the athletes' evaluations of their head coaches' TC, whereas the other manifestations did not contribute significantly to this relationship. When individual and team levels are considered jointly, offensive scope of responsibilities and role evaluation were the best predictors for the relationship between higher perceptions of role ambiguity and weaker perceptions of TC (i.e., $\Delta \chi^{2}$ ModelsC-B $=27.823, p<.001$, and $\Delta \chi^{2}$ ModelsC-B $=19.184, p<.001$, respectively). The other manifestations of role ambiguity, except for role consequences in defense, also predicted this relationship but to a lesser extent.

When all components of role ambiguity are entered at the same time in the equation (see Table 3, Model D), only scope of responsibilities in the offensive context and evaluation in the defensive context predicted the athletes' evaluations of their 
head coaches' TC. At the team level, in comparison with Model B, improvement in the amount of explained variance in TC is $2.67 \%$ (i.e., [0.225-0.219]/0.225) and $11.11 \%$ (i.e., [0.225-0.200]/0.225) in offensive and defensive contexts, respectively. When all manifestations of role ambiguity were added in the equation, the new model (Model D) did not fit better than the more parsimonious Model C $\left(\Delta \chi^{2}\right.$ ModelsD-CScope $=2.727, p>.05$, in offensive context, and $\Delta \chi^{2}$ ModelsD-CEvaluation $=$ $2.290, p>.05$, in defensive context).

\section{Role Ambiguity and Game Strategy Competence (GSC)}

Results for the multilevel analysis of GSC are presented in Tables 4 and 5. For Model A, 34\% of the variance in GSC was explained at the team level (ICC) and $66 \%$ of the variance was explained at the individual level. The introduction of "status," "gender," and their interaction (Model B) did not improve the model (i.e., $\Delta \chi^{2}$ ModelsB-A $\left.=3.082, p>.05\right)$. The successive introduction of each manifestation of role ambiguity in the equation (Model C) increased the adequacy of the data to the suggested model (see Table 4; significant variations of the $\chi^{2}$ with $p<.001$ and $\beta$ significant with $p<.01$ ). The positive sign of the $\beta$ indicated that weaker perceptions of role ambiguity, for all manifestations in both contexts, were associated with higher perceptions of game strategy competence.

At the individual level, in the offensive context (after controlling for "status," "gender," and their interaction), 10.59\% (i.e., [0.699-0.625]/0.699) of the variance of GSC was explained by scope of responsibilities, 6.72\% (i.e., [0.699-0.652]/0.699) by role behaviors, $8.15 \%$ (i.e., [0.699-0.642]/0.699) by role evaluation, and $5.44 \%$ (i.e., [0.699-0.661]/0.699) by role consequences. In the defensive context, $8.30 \%$ (i.e., [0.699-0.641]/0.699) of the variance of GSC was explained by scope of responsibilities, $9.30 \%$ (i.e., [0.699-0.634]/0.699) by role behaviors, $8.44 \%$ (i.e., [0.699-0.640]/0.699) by role evaluation, and 3.86\% (i.e., [0.699-0.672]/0.699) by role consequences. Thus, at the individual level, the manifestations of role ambiguity negatively predicted GSC.

At the team level, in the offensive context (after controlling for "status," "gender," and their interaction), 5.65\% (i.e., [0.354-0.334]/0.354) of the variance of GSC was explained by scope of responsibilities, $1.69 \%$ (i.e., [0.354-0.348]/0.354) by role behaviors, $10.45 \%$ (i.e., [0.354-0.317]/0.354) by role evaluation, and none by role consequences. In the defensive context, only role evaluation explained a part of the variance of GSC, $12.71 \%$ (i.e., [0.354-0.309]/0.354). Thus, the results indicated that at the team level, the different components of role ambiguity in offensive context and role evaluation in defense negatively predicted GSC. When the two levels are considered jointly (i.e., individual and team), the overall results revealed that scope of responsibilities and role evaluation in the offensive context and role evaluation in the defensive context contributed the most to the negative relationship between role ambiguity and GSC (i.e., $\Delta \chi^{2}$ ModelsC-B $=23.362, p<.001$, $\Delta \chi^{2}$ ModelsC-B $=21.503, p<.001$, in offensive context, respectively, and $\Delta \chi^{2}$ ModelsC-B $=20.562, p<.001$ for role evaluation in defensive context). Nevertheless, all the other role ambiguity manifestations also predicted this relationship.

Again, when all components of role ambiguity are entered at the same time in the equation (see Table 5, Model D), only scope of responsibilities in the offensive context and evaluation in the defensive context predicted the athletes' 
evaluations of their head coaches' GSC. At the team level, in comparison with Model B, improvement in the amount of explained variance in GSC is $8.19 \%$ (i.e., [0.354-0.325]/0.354) and 5.65\% (i.e., [0.354-0.334]/0.354) in offensive and defensive contexts, respectively. When all manifestations of role ambiguity were added in the equation the new model (Model D) did not fit better than the "more parsimonious" Model C $\left(\Delta \chi^{2}\right.$ ModelsD-CScope $=3.300, p>.05$, in offensive context, and $\Delta \chi^{2}$ ModelsD-CEvaluation $=3.796, p>.05$, in defensive context). As a final note, when the model allowed the slopes to vary, a nonsignificant reduction in the $\chi^{2}$ statistic was found. The results revealed that fitting random slopes did not improve on the random intercept model. Therefore, these results were not reported or discussed.

\section{Discussion}

The general purpose of the current study was to examine the relationship between the focal person's (i.e., athlete's) perceptions of role ambiguity and his or her evaluation of the role sender's (i.e., coach's) coaching competency at individual and group levels. Using hierarchical linear models, evidence pertaining to the existence of a negative relationship between role ambiguity and coaching competency at both individual and group levels was provided. When the levels are considered jointly, athletes perceiving greater ambiguity in their role (scope of responsibilities, role evaluation, role behaviors, and role consequences) in both offensive and defensive contexts were more critical of their coach's capacities to lead their team during competitions (game strategy competence) and to diagnose or formulate instructions during training sessions (technique competence). Role ambiguity associated with scope of responsibilities and role evaluation constituted the manifestations of role ambiguity most associated to the two dimensions of coaching competency considered in the current study. These results supported the hypothesized connections between perceptions of role ambiguity and athletes' cognitive responsesoperationalized by perceptions of coaching competency in this study-that were postulated in the role episode model (Kahn et al., 1964).

An important contribution of this study pertains to the demonstrated strengths of the role ambiguity-coaching competency relationship as well as the manifestations of role ambiguity that were most salient in the analyses. As it pertains to the strength of the relationship, 53-61\% of the variance of TC and GSC was explained by the four manifestations of role ambiguity in offensive and defensive contexts at the individual level, whereas only 25-33\% of the variance of TC and GSC was explained by three of the four manifestations of role ambiguity in the two contexts at the group level. The fact that the strength of the relationship was higher at the individual level is in line with the previous studies that have examined the relationship between role ambiguity or coaching competency and another correlate from a multilevel perspective (Beauchamp, Bray, Fielding, \& Eys, 2005; Myers et al., 2011; Myers, Wolfe, et al., 2006). In these previous studies, stronger relationships were also supported at the individual level, except in the Myers et al.'s (2011) research where more balanced results were noted. Taken together, the results of the current study lead us to suggest that members select and integrate more individual than group related information when they develop perceptions of role ambiguity and coaching competency. 
However, two methodological points may also explain the difference in the strength of the relationship according to the level of analysis. First, due to the differences in the rating scale structure of the two questionnaires, all variables were standardized. As a result, the differences between teams might have been reduced. Second, the number of teams in the sample (i.e., 26) did not allow the examination of the construct validity of the two questionnaires with an exploratory multilevel confirmatory factor analysis (Hox \& Maas, 2001). Thus, if confirmatory factor analyses supported the different role ambiguity and coaching competency dimensions at the individual level, they did not indicate whether these dimensions existed at the team level. Without any indication about the construct validity of the two questionnaires at the team level, results at this level of analysis must be taken with caution and future research is needed.

As it pertains to the salience of dimensions within the relationships, scope of responsibilities and, to a lesser extent, the three remaining dimensions of role ambiguity were related to coaching competency (i.e., TC and GSC) at an individual level, although it is important to highlight that perceptions of ambiguity pertaining to role evaluation in offense and defense were the main contributors to the relationship with coaching competency at a group level. At each level, the contribution of different dimensions to the relationship between role ambiguity and coaching competency results from the process by which teammates' perceptions are built. Role ambiguity perceptions are a product of members' selection and integration of individual- and group-related information. But the ratio of these two types of information may vary in each dimension. On one hand, scope of responsibilities may comprise more individual-related information, because it reflects what is expected for each athlete in terms of specific responsibilities to fulfill. Role evaluation, on the other hand, may comprise more group-related information, because a coach may use the same criteria/methods to assess players fulfilling their roles (e.g., Beauchamp et al., 2002; Eys et al., 2006). As a result, scope of responsibilities explains a larger percentage of coaching competency at an individual level whereas role evaluation explains a larger percentage of coaching competency at the team level.

Another point that begs further investigation is that group perceptions of ambiguity surrounding evaluative processes may reflect inequities in these processes across the group (e.g., the coach's treatment/evaluation of players in response to similar behaviors is not equitable). Inequities may result from a cycle of the selffulfilling prophecy during which a coach forms expectations of athletes, adapts his or her behaviors according to his or her expectations, and treats athletes differentially (for a review, see Horn, Lox, \& Labrador, 2009). The differential treatment experienced by athletes may be viewed as a source of coaching competency. Furthermore, another theoretical construct that may illuminate the relationship between role evaluation and coaching competency at the team level is the motivational climate, that is, the situational goal structure of the environment created by a coach. The development of an ego motivational climate emphasizing interpersonal competition, rivalrous social exchanges, and social comparison influences players' perceptions of group processes (e.g., Heuzé, Sarrazin, Masiero, Raimbault, \& Thomas, 2006; for a discussion about motivational climate and group processes, see Harwood \& Beauchamp, 2007) and may induce perceptions of inequity within a team. Future studies may examine these two lines of research. 
Finally, pertaining to the context in which role ambiguity occurred, perceptions in offense (as compared with defense) explained twice the variance in TC at an individual level and nearly twice the variance in GSC at a group level. The salience of role ambiguity perceptions in the context of offense is consistent within sport literature over the past decade. Several researchers highlighted this specific finding in their studies examining role ambiguity perceptions with other constructs such as cohesion (Eys \& Carron, 2001), competitive state anxiety (Beauchamp, Bray, Eys, \& Carron, 2003), and athlete satisfaction (Eys, Carron, Bray, \& Beauchamp, 2003). It was speculated that the offensive context may be one that has more responsibilities, greater complexity with respect to decision making, and is a focus for coaches in training situations, thus affording greater opportunities for ambiguity to develop. In addition, they encouraged future research to examine this issue in more depth, which is a suggestion that is further supported through the results of the current study.

Despite the contributions of the current research, a number of limitations should also be noted. First, a cross-sectional design was used in the current study precluding any conclusion about the causal sequence between the two constructs. In the role episode model, Kahn et al. (1964) supposed that perceptions of role ambiguity influenced interpersonal relations between the focal person and the role sender but also that these relations affected the focal person's perceptions of ambiguity. Thus, future research using a longitudinal design should examine a possible reciprocal relationship between role ambiguity and coaching competency. However, Kahn et al. also advanced that interpersonal relations affected the interactions between the role sender and the focal person. Based on their model, it would be relevant to consider a possible moderating effect of coaching competency on the relationship between coaches' behaviors and athletes' perceptions of ambiguity. Nevertheless, another theoretical model that is concerned with coaching effectiveness (i.e., the working model of coaching effectiveness; Horn, 2008) suggested that the relationship between coaches' behaviors and athletes' self-perceptions, beliefs, and attitudes are mediated by athletes' perceptions and evaluation of coaches' behaviors. Thus, another possibility would be that perceptions of coaching competency mediate the relationship between coaches' behaviors and athletes' perceptions of role ambiguity. Future studies should examine these competing hypotheses.

Second, only two of the five dimensions of Myers et al.'s (2010) coaching competency construct that were considered to be the most related to role involvement in sport settings were included in the current study. However, in the role episode model (Kahn et al., 1964), the process of communicating role expectations has important implications in the way players experience role ambiguity. Thus, another dimension that could be considered in future research might be perceptions of the coaches' communication competence (e.g., Burke, 2005) in relation to teammates' perceptions of role ambiguity - a dimension not currently assessed within the Coaching Competency Scale.

Third, the sample was obtained from a French population and was mainly young adults. Thus, the results cannot be generalized to other cultures and to younger/older athletes. Fourth, the data screening process resulted in the exclusion of respondents (i.e., outliers) with lower perceptions of role clarity and coaching competency compared with those who remained for subsequent analyses. However, 
it is not believed that this limitation would have a major effect on the relationships between the two constructs under examination. Fifth, the size of the sample and its unbalanced gender and status composition did not allow an examination of the relationship separately for men, women, starters, and nonstarters. Given that previous studies have revealed that role ambiguity and leadership perceptions differ according to gender (e.g., Beauchamp et al., 2003; Chelladurai \& Saleh, 1978; Cunningham \& Eys, 2007; Eys \& Carron, 2001) and status (e.g., Beauchamp \& Bray, 2001; Beauchamp, Bray, Eys, \& Carron, 2005; Chelladurai, 1990), it would be of interest to consider the relationship between role ambiguity and coaching competency within each subsample (i.e., men, women, starters, and nonstarters). These different limitations provide opportunities for future research to replicate our methods with other populations, design, and larger samples.

\section{Notes}

1. Originally, the authors defined CBC as athletes' evaluations of their head coach's ability to influence their personal development and positive attitudes toward sport. This definition was revised by Myers, Chase, Beauchamp, and Jackson (2010) to improve its clarity.

2. Originally, the authors defined TC as athletes' evaluations of their head coach's instructional and diagnostic abilities. However, during the examination of the construct validity of the Coaching Competency Scale, the authors noted an overlap between TC and GSC (i.e., correlation of .92 between the two factors). To lessen the overlap, the authors suggested altering this definition to focus on evaluating one's instructional and diagnostic abilities during practices.

\section{References}

Akaike, H. (1973). Information theory and an extension of the maximum likelihood principle. In B.N. Petrov \& P. Ciaki (Eds.), $2^{\text {nd }}$ International Symposium on Information Theory (pp. 267-81). Budapest: Akadémiai Kiadó.

Arbuckle, J.L. (1999). AMOS 4. Chicago, IL: Small Waters Corporation.

Beauchamp, M.R., \& Bray, S.R. (2001). Role ambiguity and role conflict within interdependent teams. Small Group Research, 32, 133-157. doi:10.1177/104649640103200202

Beauchamp, M.R., Bray, S.R., Eys, M.A., \& Carron, A.V. (2002). Role ambiguity, role efficacy, and role performance: Multidimensional and mediational relationships within interdependent sport teams. Group Dynamics, 6, 229-242. doi:10.1037/10892699.6.3.229

Beauchamp, M.R., Bray, S.R., Eys, M.A., \& Carron, A.V. (2003). The effect of role ambiguity on competitive state anxiety. Journal of Sport \& Exercise Psychology, 25, 77-92.

Beauchamp, M.R., Bray, S.R., Eys, M.A., \& Carron, A.V. (2005). Leadership behaviors and multidimensional role ambiguity perceptions in team sports. Small Group Research, 36, 5-20. doi:10.1177/1046496404266684

Beauchamp, M.R., Bray, S.R., Fielding, A., \& Eys, M.A. (2005). A multilevel investigation of the relationship between role ambiguity and role efficacy in sport. Psychology of Sport and Exercise, 6, 289-302. doi:10.1016/j.psychsport.2004.03.002

Bentler, P.M. (1990). Comparative fit indices in structural models. Psychological Bulletin, 107, 238-246. PubMed doi:10.1037/0033-2909.107.2.238

Bentler, P.M., \& Bonett, D.G. (1980). Significance tests and goodness of fit in the analysis of covariance structures. Psychological Bulletin, 88, 588-606. doi:10.1037/00332909.88.3.588 
Bosselut, G. (2008). Antécédents et conséquences de l'ambiguïté du rôle en contexte sportif [Antecedents and consequences of role ambiguity in sport teams] (Unpublished doctoral thesis). Université Joseph Fourier, Grenoble, France.

Bosselut, G., Heuzé, J.P., \& Sarrazin, P. (2010). Structure of the role ambiguity framework and validity in the French culture. Psychology of Sport and Exercise, 11, 471-478. doi:10.1016/j.psychsport.2010.06.001

Browne, M.W., \& Cudeck, R. (1989). Single sample cross-validation indices for covariance structures. Multivariate Behavioral Research, 24, 445-455. doi:10.1207/ s15327906mbr2404_4

Browne, M.W., \& Cudeck, R. (1993). Alternate ways of assessing model fit. In K.A. Bollen \& J.S. Long (Eds.), Testing structural equation models (pp. 136-162). Newbury Park, CA: Sage.

Burke, K.L. (2005). But coach doesn't understand: Dealing with team communication quagmires. In M.B. Andersen (Ed.), Sport psychology in practice (pp. 45-60). Champaign, IL: Human Kinetics.

Chelladurai, P. (1990). Leadership in sports: A review. International Journal of Sport Psychology, 21, 328-354.

Chelladurai, P., \& Saleh, P. (1978). Preferred leadership in sports. Canadian Journal of Applied Sport Sciences, 3, 85-92.

Chelladurai, P., \& Saleh, P. (1980). Dimensions of leader behavior in sports: Development of a leadership scale. Journal of Sport Psychology, 2, 34-45.

Cunningham, I., \& Eys, M.A. (2007). Role ambiguity and intra-team communication in interdependent sport teams. Journal of Applied Social Psychology, 37, 2220-2237. doi:10.1111/j.1559-1816.2007.00256.x

Eys, M.A., Beauchamp, M.R., \& Bray, S.R. (2006). A review of team roles in sport. In S. Hanton \& S. Mellalieu (Eds.), Literature reviews in sport psychology (pp. 227-255). Hauppauge, NY: Nova Science Publishers.

Eys, M.A., \& Carron, A.V. (2001). Role ambiguity, task cohesion, and task self-efficacy. Small Group Research, 32, 356-373. doi:10.1177/104649640103200305

Eys, M.A., Carron, A.V., Beauchamp, M.R., \& Bray, S.R. (2005). Athletes' perceptions of the sources of role ambiguity. Small Group Research, 36, 383-403. doi:10.1177/1046496404268533

Eys, M.A., Carron, A.V., Bray, S.R., \& Beauchamp, M.R. (2003). Role ambiguity and athlete satisfaction. Journal of Sports Sciences, 21, 391-401. PubMed doi:10.1080/0264041031000071137

Feltz, D.L., Chase, M.A., Moritz, S.E., \& Sullivan, P.J. (1999). A conceptual model of coaching efficacy: Preliminary investigation and instrument development. Journal of Educational Psychology, 91, 765-776. doi:10.1037/0022-0663.91.4.765

Feltz, D.L., Short, S.E., \& Sullivan, P.J. (2008). Self-efficacy in sport: Research and strategies for working with athletes, teams, and coaches. Champaign, IL: Human Kinetics.

Harwood, C., \& Beauchamp, M.R. (2007). Group functioning through optimal achievement goals. In M.R. Beauchamp \& M.A. Eys (Eds.), Group dynamics advances in sport and exercise psychology: Contemporary themes (pp. 201-219). Oxford: Routledge.

Heuzé, J.P., Sarrazin, P., Masiero, M., Raimbault, N., \& Thomas, J.P. (2006). The relationships of perceived motivational climate to cohesion and collective efficacy in elite female teams. Journal of Applied Sport Psychology, 18, 201-218. doi:10.1080/10413200600830273

Horn, T.S. (2008). Coaching effectiveness in the sport domain. In T.S. Horn (Ed.), Advances in sport psychology (3rd ed., pp. 239-268). Champaign, IL: Human Kinetics.

Horn, T.S., Lox, C., \& Labrador, F. (2009). The self-fulfilling prophecy theory: When coaches' expectations become reality. In J. Williams (Ed.), Applied sport psychology: Personal growth to peak performance (6th ed., pp. 81-107). New York: McGraw-Hill. 
Hox, J.J., \& Maas, C.J.M. (2001). The accuracy of multilevel structural equation modeling with pseudobalanced groups and small samples. Structural Equation Modeling, 8, 157-174. doi:10.1207/S15328007SEM0802_1

Kahn, R.L., Wolfe, D.M., Quinn, R.P., Snoek, J.D., \& Rosenthal, R.A. (1964). Organizational stress: Studies in role conflict and ambiguity. New York: John Wiley \& Sons.

Kashy, D.A., \& Kenny, D.A. (2000). The analysis of data from dyads and groups. In H.T. Reis \& C.M. Judd (Eds.), Handbook of research methods in social and personality psychology (pp. 451-477). Cambridge, England: Cambridge University Press.

Mellalieu, S.D., \& Juniper, S.W. (2006). A qualitative investigation into experiences of the role episode in soccer. The Sport Psychologist, 20, 399-418.

Myers, N.D., Beauchamp, M.R., \& Chase, M.A. (2011). Coaching competency and satisfaction with the coach: A multilevel structural equation model. Journal of Sports Sciences, 29, 411-422. PubMed doi:10.1080/02640414.2010.538710

Myers, N.D., Chase, M.A., Beauchamp, M.R., \& Jackson, B. (2010). Athletes' perceptions of coaching competency scale II-High school teams. Educational and Psychological Measurement, 70, 477-494. doi:10.1177/0013164409344520

Myers, N.D., Feltz, D.L., Maier, K.S., Wolfe, E.W., \& Reckase, M.D. (2006). Athletes' evaluations of their head coach's coaching competency. Research Quarterly for Exercise and Sport, 77, 111-121. PubMed doi:10.5641/027013606X13080769704082

Myers, N.D., Wolfe, E.W., Maier, K.S., Feltz, D.L., \& Reckase, M.D. (2006). Extending validity evidence for multidimensional measures of coaching competency. Research Quarterly for Exercise and Sport, 77, 451-463. PubMed doi:10.5641/0270136 06X13080770015247

Papaioannou, A., Marsh, H.W., \& Theodorakis, Y. (2004). A multilevel approach to motivational climate in physical education and sport settings: An individual or a group level construct? Journal of Sport \& Exercise Psychology, 26, 90-118.

Rasbash, J., Browne, W., Goldstein, H., Yang, M., Plewis, I., \& Healy, M., . . Lewis, T. (2000). A user's guide to MlwiN (version 2.1a): Multilevel models project. London: Institute of Education, University of London.

Raudenbush, S.W., \& Bryk, A.S. (2002). Hierarchical linear models: Applications and data analysis methods (2nd ed.). Thousand Oaks, CA: Sage.

Tabachnick, B.G., \& Fidell, L.S. (2007). Using multivariate statistics (5th ed.). Boston: Allyn and Bacon.

Zumbo, B.D., Gadermann, A.M., \& Zeisser, C. (2007). Ordinal version of coefficients alpha and theta for Likert rating scales. Journal of Modern Applied Statistical Methods; JMASM, 6, 21-29.

Manuscript submitted: March 14, 2011

Revision accepted: February 24, 2012 